\title{
Variações florística e estrutural e relações fitogeográficas de um fragmento de floresta decídua no Rio Grande do Norte, Brasil
}

\author{
Luiz Antonio Cestaro ${ }^{1,3}$ e João Juares Soares ${ }^{2}$
}

Recebido em 12/11/2002. Aceito em 05/08/2003

RESUMO - (Variações florística e estrutural e relações fitogeográficas de um fragmento de floresta decídua no Rio Grande do Norte, Brasil). O trabalho foi realizado num fragmento de floresta decídua com cerca de 270 ha centrado em $5^{\circ} 53^{\prime} \mathrm{S}$ e $35^{\circ} 23^{\prime} \mathrm{W}$ e que se estende por dois ambientes edáficos distintos (Moda 1 e Moda 2). Os objetivos do trabalho foram caracterizar florística e estruturalmente o componente arbóreo nos dois ambientes, compará-los entre si e avaliar suas relações fitogeográficas. Todos os indivíduos vivos e mortos em pé com perímetro à altura do peito $\geq 10 \mathrm{~cm}$ foram considerados como árvore e amostrados pelo método dos quadrantes. Para Moda 1 e Moda 2

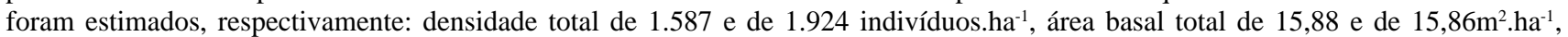
freqüências modais das alturas entre 5 e 5,9m e entre 6 e $6,9 \mathrm{~m}$ e dos diâmetros de caule entre 5,0 e 9,9cm e entre 3,2 e 4,9cm, índice de diversidade de Shannon de 3,19 e de 3,26 e índice de eqüabilidade de Pielou de 0,79 e de 0,86. Os estratos arbóreos nos dois ambientes foram considerados estruturalmente semelhantes. Foram observadas no total 66 espécies de árvores, sendo 56 em Moda 1 e 45 em Moda 2. Piptadenia moniliformis Benth. é a espécie com maior valor de importância nas duas áreas, seguidas por Tabebuia impetiginosa (Mart. ex DC.) Standl. em Moda 1 e por Chamaecrista ensiformis (Vell.) H.S. Irwin \& Barneby em Moda 2. As áreas apresentam grande similaridade florística $\left(\mathrm{S}_{\mathrm{S}}=0,69\right.$ e $\left.\mathrm{S}_{\mathrm{C}}=0,53\right)$, sendo que as espécies características de matas decíduas são mais abundantes em ou exclusivas de Moda 1, e as espécies características das Caatingas, em Moda 2. As pequenas diferenças florística e estrutural entre os dois setores da mata podem ser atribuídas às condições edáficas. Em termos florísticos, fisionômicos e ambientais, a mata foi classificada como um tipo de vegetação de transição entre as províncias fitogeográficas Atlântica e das Caatingas, com a presença destacada de espécies com ampla distribuição nas matas secas neotropicais e nos Cerrados.

Palavras-chave: floresta seca, fitossociologia, fitogeografia, floresta Atlântica, Caatinga

\begin{abstract}
Floristic and structural variations, and the phytogeographical relationships of a deciduous forest fragment in Rio Grande do Norte State, Brazil). This work was undertaken in a deciduous forest fragment ( 270 ha, centered on $5^{\circ} 53^{\prime} \mathrm{S}$ and $\left.35^{\circ} 23^{\prime} \mathrm{W}\right)$ spanning two distinct edaphic environments (Areas 1 and 2), and sought to floristically and structurally characterize the tree layers in both environments, as well as to assess their phytogeographical relationships. All living and standing dead trees with $\mathrm{CBH} \geq 10 \mathrm{~cm}$ were sampled using the point-centered quarter method. The results for areas 1 and 2 were, respectively: total density, 1.587 and 1.924 individual.ha $^{-1}$; total basal area, 15.88 and $15.86 \mathrm{~m}^{2} . \mathrm{ha}^{-1}$; most frequent height classes of living trees, 5-5.9m and 6-6.9m; most frequent stem diameters of living trees, 5.0-9.9cm and 3.2-4.9cm; Shannon diversity index 3.19 and 3.26; and Pielou evenness index, 0.79 and 0.86 . The tree layers in both areas 1 and 2 were considered structurally similar. A total of 66 tree species were observed (56 in area 1 and 45 in area 2). Piptadenia moniliformis Benth. showed the greatest importance value in both areas, followed by Tabebuia impetiginosa (Mart. ex DC.) Standl. in area 1, and Chamaecrista ensiformis (Vell.) H.S. Irwin \& Barneby in area 2. Both edaphic environments showed a high floristic similarity $\left(\mathrm{S}_{\mathrm{S}}=0.69\right.$ and $S_{C}=0.53$ ). Species typical of deciduous forests were more abundant in, or exclusive to, area 1. Species more typical of Caatingas environments were more abundant in, or exclusive to, area 2 . The small floristic and structural differences noted between the two areas are apparently attributable to soil conditions. This forest fragment contains many species showing wide distributions in both Neotropical dry forests and Cerrados, and was considered a transitional vegetation type between the Atlantic and Caatingas phytogeographical provinces, in terms of species composition and physiognomy, as well as local environment conditions.
\end{abstract}

Key words: dry forest, phytosociological analysis, phytogeography, Atlantic Forest, Caatinga

\section{Introdução}

As florestas tropicais decíduas, ou florestas secas, envolvem conjunto muito grande de tipos florestais interpostos entre as florestas tropicais pluviais e as savanas e desertos. Não existem limites climáticos rígidos determinando a ocorrência das florestas tropicais decíduas. Gerhardt \& Hytterborn (1992) sugerem como balizadores as principais precipitações anuais entre 400 e $1.700 \mathrm{~mm}$ e o período seco com cerca de seis meses estendendo-se por uma ou duas estações. Além disso, a variabilidade interanual da

\footnotetext{
1 Departamento de Geografia, CCHLA, Universidade Federal do Rio Grande do Norte, C. Postal 1528, CEP 59078-970, Natal, RN, Brasil

2 Departamento de Botânica, Centro de Ciências Biológicas e da Saúde, Universidade Federal de São Carlos, Rod. Washington Luiz km 235, CEP 13565-905, São Carlos, SP, Brasil (juares@ power.ufscar.br)

3 Autor para correspondência: cestaro@cchla.ufrn.br
} 
distribuição das chuvas, expondo as comunidades a estresses hídricos extremos e imprevisíveis pode, mais do que a duração da estação seca, determinar a diversidade estrutural, florística e funcional desses ecossistemas florestais (Murphy \& Lugo 1986a; Lerdau et al. 1991; Gerhardt \& Hytterborn 1992).

Se o clima determina as características da vegetação decídua ao nível de macro e mesoescala, o relevo e o solo, interferindo sobretudo na disponibilidade de água, as determinam em nível local, o que pode implicar em variação interna (Oliveira-Filho et al. 1998) e na ocorrência de encraves vegetacionais (Burnett et al. 1998; Ivanauskas et al. 2000).

As florestas decíduas neotropicais têm sido estudadas com maior intensidade na América Central, onde ocupavam originalmente $50 \%$ dos ambientes florestais (Murphy \& Lugo 1986b; Sabogal 1992; Gillespie et al. 2000). Na América do Sul, representam cerca de 22\% das florestas tropicais originais (Murphy \& Lugo 1986a), distribuindo-se pelo norte da Colômbia, norte da Venezuela, norte da Argentina, oeste do Paraguai, leste da Bolívia e nordeste do Brasil (Hueck \& Seibert 1981).

As florestas decíduas brasileiras ocorrem geralmente como faixas transicionais estreitas e descontínuas separando as florestas pluviais perenifólias e semidecíduas amazônicas e atlânticas das savanas dos Cerrados e das savanas-estépicas das Caatingas (IBGE 1992; 1993; Ratter 1992). Em sentido amplo, essas matas são agrupadas sob as denominações gerais Floresta Estacional Decidual (IBGE 1992), florestas caducifólias e matas ou florestas secas (Rizzini 1979; Fernandes 1998).

No nordeste brasileiro, a floresta Estacional Decidual ocorre bordejando a Floresta Semidecidual e esta, a Floresta Ombrófila (Andrade-Lima 1960). Está presente também ao longo de toda a zona de contato entre as Caatingas e os Cerrados (IBGE 1993), acompanhando a isoieta de $1.000 \mathrm{~mm}$ de precipitação anual (Nimer 1972). A classificação fitogeográfica dessas matas decíduas é controversa, sendo algumas vezes associadas à província Atlântica (Andrade-Lima 1960) e outras às Caatingas (Egler 1957) e outras ainda consideradas como conjunto florestal independente (Fernandes 1998). A dificuldade provavelmente está relacionada ao caráter transicional, às pequenas áreas que ocupam, à devastação quase total e, sobretudo, à grande falta de conhecimento que as envolvem. No Rio Grande do Norte, as informações sobre esse tipo florestal restringem-se a breves descrições e indicações cartográficas um tanto imprecisas da sua existência
(Jacomine et al. 1971; Salgado et al. 1981).

Estudos em florestas de transição são importantes sob diferentes aspectos. Além de fornecerem informações sobre a composição, a riqueza e a diversidade de espécies adaptadas a ambientes relativamente instáveis, subsidiam o aprimoramento dos sistemas de classificação da vegetação e possibilitam avaliar com maior precisão a dinâmica dos principais tipos florestais contíguos, resgatando variações passadas e projetando reações futuras.

Os objetivos deste trabalho são descrever florística e estruturalmente o componente arbóreo de um fragmento de Floresta Estacional Decidual no Rio Grande do Norte, analisar sua variação florística e estrutural interna em função de dois tipos distintos de relevo e de solo, e avaliar a participação dos elementos das províncias fitogeográficas próximas na sua composição.

\section{Material e métodos}

Local do estudo - $\mathrm{O}$ fragmento florestal tem cerca de 270ha (coordenadas centrais $5^{\circ} 53^{\prime} \mathrm{S}$ e $35^{\circ} 23^{\prime} \mathrm{W}$ e altitude média de $40 \mathrm{~m}$ ), está localizado a $25 \mathrm{~km}$ do oceano Atlântico, no município de Macaíba, RN e pertence ao Colégio Agrícola de Jundiaí. Um de seus trechos é conhecido como mata do Olho d'Água, razão pela qual essa denominação é estendida neste trabalho à área de estudo, que passa a ser citada através do acrônimo Moda. A mata é classificada, segundo o IBGE (1992), como Floresta Estacional Decidual de Terras Baixas, com deciduidade ao final do período desfavorável atingindo mais de $80 \%$ de um dossel não muito compacto. Certos trechos da Moda vêm sendo explorados há várias décadas para a retirada de estacas e mourões, utilizados na manutenção das cercas da propriedade. $\mathrm{O}$ abate de troncos é seletivo em diâmetro e espécies e é realizado de forma a permitir o rebrote das árvores, o que tem garantido a sustentabilidade da exploração. A mata é utilizada também para o pastejo de gado bovino, sobretudo durante a estação seca. Seu estado de conservação, todavia, parece razoável, tendo em vista a cobertura arbórea contínua, sem a dominância aparentemente marcante de uma única espécie e a presença freqüente de árvores jovens. $\mathrm{O}$ clima local é uma transição entre os tipos As' e BSh' da classificação de Köppen, com temperaturas elevadas ao longo de todo o ano e chuvas no outono e no inverno. A temperatura média anual do ar inferida para a área está em torno de $26^{\circ} \mathrm{C}$, e a temperatura média mensal é relativamente uniforme ao longo do 
ano (Nimer 1972). No posto pluviométrico da Empresa de Pesquisa Agropecuária do Rio Grande do Norte (EMPARN), localizado $6 \mathrm{~km}$ a nordeste da Moda, a precipitação média anual para o período 1984-2000 foi de $1.227 \mathrm{~mm}$, com coeficiente de variação de $30 \%$. De setembro a dezembro as precipitações médias mensais foram menores que $50 \mathrm{~mm}$, respondendo por menos de $9 \%$ da precipitação média anual e delimitando uma estação seca com duração média de quatro meses. A amplitude altimétrica do terreno por onde se estende a mata não é superior a $20 \mathrm{~m}$.

O espaço ocupado pela Moda foi separado em dois ambientes em função da dinâmica geomorfológica. Um ambiente, denominado neste trabalho Moda 1, é o mais extenso e envolve as porções mais elevadas do terreno, com relevo de suave ondulado a ondulado, geralmente com exposição N-NW e sujeito a erosão mais intensa. O outro ambiente, denominado Moda 2, ocupa as partes mais baixas do terreno, apresenta relevo de plano a suave ondulado, com leve inclinação em direção $\mathrm{NW}$ e recebe a maior parte do material erodido de Moda 1. Os levantamentos concentraramse nos trechos mais conservados, onde os vestígios de exploração eram menos evidentes.

Caracterização dos solos - Amostras de solo nas profundidades de $10-20 \mathrm{~cm}$ e $60-80 \mathrm{~cm}$ em Moda $1 \mathrm{e}$ de $10-20 \mathrm{~cm}, 60-80 \mathrm{~cm}$ e $100-120 \mathrm{~cm}$ em Moda 2, uma para cada profundidade, foram coletadas com trado de caneco. Não foi possível coletar solo na profundidade de $100-120 \mathrm{~cm}$ em Moda1 devido à grande quantidade de seixos rolados na massa do solo, o que impossibilitou o avanço do trado. As amostras foram analisadas química e granulometricamente no Laboratório de Análises de Solo, Água e Planta da EMPARN, de acordo com os métodos adotados pela EMBRAPA (1997). O teor relativo dos nutrientes foi considerado a partir de Malavolta \& Kliemann (1985), Malavolta (1992) e EMBRAPA (1999). O solo em cada área foi classificado de acordo com EMBRAPA (1999) a partir de tradagens e das análises físicoquímicas.

Caracterização da vegetação - Os dados foram coletados usando-se o método de quadrantes centrados em um ponto (Cottam \& Curtis 1956). Em Moda 1 e em Moda 2 foram instalados, respectivamente, $135 \mathrm{e}$ 65 pontos ao longo de duas transecções, com distanciamento de $10 \mathrm{~m}$ entre pontos. Os quadrantes foram orientados aleatoriamente em cada ponto e em cada quadrante a árvore viva ou morta em pé mais próxima do ponto foi marcada com uma placa numerada. Considerou-se como árvore todo indivíduo cujo caule lenhoso apresentasse PAP (perímetro na altura de $1,3 \mathrm{~m}$ do solo) $\geq 10 \mathrm{~cm}$. Para cada indivíduo foi coletado material botânico para identificação, medido o PAP, estimada a altura por comparação com uma vara de $10 \mathrm{~m}$ de comprimento e medida, a $0,3 \mathrm{~m}$ de altura, a menor distância até o ponto. Para os indivíduos ramificados abaixo de $1,3 \mathrm{~m}$ foram medidos todos os ramos vivos com PAP $\geq 10 \mathrm{~cm}$. Nos quadrantes em que uma árvore morta em pé foi amostrada, considerou-se também a árvore viva mais próxima ao ponto e procedeu-se da mesma forma que para as demais incluídas no levantamento. A distância corrigida do indivíduo ao ponto foi calculada adicionando-se à distância obtida no campo o raio da seção transversal do tronco, calculado a partir do perímetro, conforme sugerido por Martins (1991). A distância média indivíduo-ponto, resultado da média aritmética das distâncias corrigidas (Cottam \& Curtis 1956) foi calculada para o total de árvores vivas amostradas.

Material fértil das espécies arbóreas observadas na mata foi coletado ao longo de 1999-2001. A identificação das espécies foi realizada a partir de literatura apropriada, consulta a especialistas e comparação com exsicatas depositadas nos herbários IPA, JPB, PEUFR, UFP e ESAL (Holmgren et al. 1990). O material botânico foi incorporado à coleção do Departamento de Geografia da UFRN e duplicatas foram depositadas no Herbário IPA.

A suficiência amostral em cada uma das áreas foi considerada em relação à amostra florística e à amostra de distâncias indivíduo-ponto. A representatividade florística foi analisada por intermédio da curva de incremento de espécies por ponto, proposta por Martins (1991) para o método dos quadrantes. Para Moda 1 o acréscimo de $23,8 \%$ de pontos (últimos 26 pontos em relação aos primeiros 109) implicou na adição de mais duas espécies (4,2\%). Para Moda 2 o acréscimo de $18,2 \%$ de pontos (últimos 10 pontos em relação aos primeiros 55) implicou na adição de mais uma espécie $(2,6 \%)$. Esses valores indicam que as amostras são suficientes para a representação florística das duas áreas, segundo os critérios propostos por MuellerDombois \& Ellenberg (1974). A representatividade da distância indivíduo-ponto foi avaliada a partir do erro padrão da média/média (Mueller-Dombois \& Ellenberg 1974). Para as 135 distâncias levantadas em Moda 1 foi obtido um erro padrão de $2,76 \%$ e para as 65 distâncias de Moda 2, de 3,94\%. Esses valores foram considerados satisfatórios, segundo critério adotado por Cottam \& Curtis (1956). 
As espécies foram classificadas segundo seu habitat preferencial nas seguintes categorias: grupo 1 - espécies com distribuição ampla pelas florestas estacionais neotropicais, podendo estender-se pelas florestas ombrófilas, grupo 2 - espécies presentes nas florestas estacionais e/ou ombrófilas da província Atlântica em seu sentido amplo, segundo Fernandes (1998), grupo 3 - espécies mais freqüentes nas savanas-estépicas florestadas e/ou arborizadas da província das Caatingas, grupo 4 - espécies que ocorrem nas savanas florestadas (cerradão) da província dos Cerrados, grupo 5 - espécies que ocorrem simultaneamente nos grupos 3 e 4 anteriores. A classificação das espécies foi feita a partir das informações obtidas dos exemplares depositados nos herbários visitados e relacionados acima e a partir da consulta a estudos taxonômicos (Furlan 1996; Gentry 1992; Landrum 1986; Lewis 1998; Pirani 1999; Sleumer 1980; 1984; Zappi 1994), florísticos (Andrade-Lima 1953; 1954; 1960; Barbosa et al. 1996; Chiappeta 1985; Costa 1996; Costa e Silva 1996; Du Bocage \& Sales 2002; Lewis 1987; Lima 1985; Lorenzi 1992; 1998; Medeiros-Costa 1982; Oliveira-Filho \& Carvalho 1993; Pereira \& Assis 2000; Pott \& Pott 1994; Prado \& Gibbs 1993; Ratter et al. 2000; Rizzini 1979; Rodrigues \& Nave 2000; Silva 1980) e fitossociológicos (Araújo et al. 1998; Carvalho et al. 2000; OliveiraFilho 1993; Rodal et al. 1998; Silva \& Nascimento 2001).

Os dados quantitativos obtidos em campo para Moda 1 e Moda 2 foram trabalhados independentemente para cada área em planilha eletrônica Microsoft $^{\oplus}$ Excel versão 97, sendo calculados: número de espécies amostradas, número de indivíduos por espécie, presença, densidade total por área, área basal por espécie e total e densidade, freqüência, dominância, valor de importância (VI) e valor de cobertura (VC) relativos por espécie, conforme procedimentos apresentados por Cavassan et al. (1984) e Martins (1991). Os parâmetros acima foram calculados duas vezes; na primeira, com o objetivo de verificar a posição das árvores mortas na estrutura de cada trecho da mata e na segunda, substituindo-se as árvores mortas pelas árvores vivas amostradas nos mesmos quadrantes, para obter-se a posição das espécies apenas entre os indivíduos vivos. A altura das árvores vivas foi agrupada em intervalos de um metro e os diâmetros, em intervalos com amplitude de $5 \mathrm{~cm}$, exceto o primeiro intervalo, que teve amplitude de $1,8 \mathrm{~cm}$. Para os indivíduos ramificados, considerou-se na distribuição diamétrica apenas o ramo mais grosso. Para cada área foram calculados o índice de diversidade H' de Shannon utilizando logaritmo natural, a partir do total de espécies registradas nos quadrantes, e o índice de equabilidade J' de Pielou, a partir do total de espécies observadas, ambos seguindo Kent \& Coker (1994).

A comparação entre Moda 1 e Moda 2, a partir das espécies presentes e de suas quantidades, foi feita através dos índices de similaridade de Sørensen $\left(\mathrm{S}_{\mathrm{S}}\right)$ e de Czekanowski $\left(\mathrm{S}_{\mathrm{C}}\right)$, segundo Kent \& Coker (1994). No cálculo de $\mathrm{S}_{\mathrm{C}}$, as espécies apenas observadas, mas ausentes nos quadrantes, foram consideradas como se tivessem ocorrido com um indivíduo no levantamento. As distribuições de frequiência das alturas e dos diâmetros das árvores das duas áreas foram comparadas através do teste estatístico de Kolmogorov-Smirnov (Zar 1999).

\section{Resultados}

Solos - Em Moda 1 o solo dominante foi classificado como um Argissolo Amarelo Distrófico, que ocupa as porções mais elevadas do terreno e tem como origem os sedimentos do grupo Barreiras, depositados durante o período Terciário (Mabesoone et al. 1972). Em Moda 2, o solo dominante é um Neossolo Flúvico Tb Distrófico formado por transporte de material erodido do Argissolo.

O Argissolo apresenta textura de franco-arenosa a franco-argilo-arenosa, com profusão de seixos rolados de quartzo com comprimento de até $10 \mathrm{~cm}$, tanto na superfície quanto na massa do solo. A fertilidade varia de baixa a média, elevando-se um pouco próximo à superfície. Possui baixa concentração de alumínio e $\mathrm{pH}$ de moderado a fortemente ácido (Tab. 1). Apresenta ainda uma camada descontínua e delgada de serapilheira, raramente ultrapassando $3 \mathrm{~cm}$ de espessura.

O Neossolo, de origem colúvio-aluvionar, é essencialmente arenoso, com pequena quantidade de seixos rolados surgindo a partir de $40 \mathrm{~cm}$ de profundidade. Os seixos apresentam dimensões menores do que aquelas observadas no Argissolo. A camada de serapilheira raramente ultrapassa $1 \mathrm{~cm}$, concentrando-se sobretudo nas partes mais baixas do micro-relevo. Quimicamente apresenta caráter epieutrófico e endoálico, em função, respectivamente, da maior fertilidade da camada superficial e do maior teor de alumínio nas camadas subsuperficiais (Tab. 1). São observados também na camada superficial $\mathrm{pH}$ maior, maior saturação de bases e maior concentração de cálcio. 
Tabela 1. Características físicas e químicas dos solos de dois trechos (Moda 1 e Moda 2) da mata do Olho d’Água, Macaíba, RN, para diferentes profundidades $\left(\mathrm{S}=\right.$ soma de bases trocáveis; $\mathrm{T}=$ capacidade de troca catiônica; $\mathrm{V}=$ saturação por bases; $\mathrm{S}_{\mathrm{Al}}=$ saturação por alumínio).

\begin{tabular}{|c|c|c|c|c|c|c|}
\hline \multirow[t]{3}{*}{ Parâmetro } & \multirow{2}{*}{\multicolumn{2}{|c|}{$\begin{array}{c}\text { Argissolo Amarelo } \\
\text { (Moda 1) }\end{array}$}} & \multirow{2}{*}{\multicolumn{3}{|c|}{$\begin{array}{l}\text { Neossolo Flúvico } \\
\text { (Moda 2) }\end{array}$}} & \multirow[t]{3}{*}{ Teor adequado } \\
\hline & & & & & & \\
\hline & 10 a 20 & 60 a 80 & 10 a 20 & 60 a 80 & 100 a 120 & \\
\hline Areia $(\%)$ & 74 & 61 & 89 & 88 & 89 & - \\
\hline Silte $(\%)$ & 15 & 17 & 7 & 6 & 0 & - \\
\hline Argila (\%) & 11 & 22 & 4 & 6 & 11 & - \\
\hline pH em água & 5,5 & 5,3 & 5,5 & 5,1 & 5,2 & $6,0-6,5$ \\
\hline $\mathrm{Al}^{3+}\left(\mathrm{cmol}_{\mathrm{c}} \cdot \mathrm{kg}^{-1}\right)$ & 0,12 & 0,25 & 0,10 & 0,60 & 0,65 & $<0,6$ \\
\hline $\mathrm{H}^{+}+\mathrm{Al}^{3+}\left(\mathrm{cmol} \cdot \mathrm{kg}^{-1}\right)$ & 5,69 & 5,03 & 2,14 & 2,14 & 1,57 & - \\
\hline $\mathrm{Ca}^{2+}\left(\mathrm{cmol}_{\mathrm{c}} \cdot \mathrm{kg}^{-1}\right)$ & 3,90 & 2,06 & 2,07 & 0,33 & 0,16 & - \\
\hline$\%$ do valor $\mathrm{T}$ & 35,6 & 25,0 & 42,7 & 11,4 & 7,5 & $>50$ \\
\hline $\mathrm{Mg}^{2+}\left(\mathrm{cmol}_{\mathrm{c}} \cdot \mathrm{kg}^{-1}\right)$ & 1,13 & 0,89 & 0,49 & 0,27 & 0,27 & - \\
\hline$\%$ do valor $\mathrm{T}$ & 10,3 & 10,8 & 10,1 & 9,3 & 12,7 & $>15$ \\
\hline \multirow{2}{*}{$\begin{array}{ll}\mathrm{K}^{+} & \left(\mathrm{cmol}_{\mathrm{c}} \cdot \mathrm{kg}^{-1}\right) \\
& \% \text { do valor } \mathrm{T}\end{array}$} & 0,20 & 0,18 & 0,12 & 0,11 & 0,08 & - \\
\hline & 1,8 & 2,2 & 2,5 & 3,8 & 3,8 & $>5$ \\
\hline \multirow{2}{*}{$\begin{aligned} \mathrm{Na}^{+} & \left(\mathrm{cmol}_{\mathrm{c}} \cdot \mathrm{kg}^{-1}\right) \\
& \% \text { do valor } \mathrm{T}\end{aligned}$} & 0,05 & 0,07 & 0,03 & 0,04 & 0,04 & - \\
\hline & 0,5 & 0,8 & 0,6 & 1,4 & 1,9 & $>6$ \\
\hline $\mathrm{PO}_{4}^{3-}\left(\mathrm{mg} \cdot \mathrm{kg}^{-1}\right)$ & 6 & 5 & 5 & 5 & 7 & $>10$ \\
\hline Valor $\mathrm{S}\left(\mathrm{cmol}_{\mathrm{c}} \cdot \mathrm{kg}^{-1}\right)$ & $5,28^{3}$ & $3,20^{3}$ & $2,71^{2}$ & $0,75^{1}$ & $0,55^{1}$ & - \\
\hline Valor T $\left(\mathrm{cmol}_{\mathrm{c}} \cdot \mathrm{kg}^{-1}\right)$ & 10,97 & 8,23 & 4,85 & 2,89 & 2,12 & - \\
\hline Valor V $(\%)$ & $48,00^{2}$ & $14,54^{1}$ & $67,75^{4}$ & $12,50^{1}$ & $5,00^{1}$ & - \\
\hline $\mathrm{S}_{\mathrm{Al}}(\%)$ & 2,22 & 7,25 & 3,56 & 44,44 & 54,17 & $<35$ \\
\hline
\end{tabular}

Teor relativo: ${ }^{1}$ muito baixo, ${ }^{2}$ baixo, ${ }^{3}$ médio e ${ }^{4}$ alto.

Florística - Foram observadas na mata 66 espécies de árvores. Em Moda 1 foram registradas 56 espécies, sendo 21 exclusivas e em Moda 2, 45, sendo 10 exclusivas (Tab. 2).

As espécies estão distribuídas em 28 famílias. Leguminosae é a família mais rica, com 14 espécies, seguida por Myrtaceae, com nove, Rubiaceae, com cinco, Flacourtiaceae com quatro e por Anacardiaceae, Bignoniaceae e Cactaceae, com três espécies cada uma. Vinte famílias ocorreram com apenas uma espécie. Eugenia, com quatro espécies, é o gênero mais rico, seguido por Casearia, com três espécies e por Alibertia, Caesalpinia, Campomanesia, Capparis, Mimosa, Myrcia, Piptadenia e Tabebuia, com duas espécies cada. Os demais 42 gêneros estão representados por apenas uma espécie. Uma espécie permanece com identificação específica insegura e seis com identificação apenas até gênero.

A distribuição das espécies presentes na Moda, segundo seu habitat preferencial, indica que 19 espécies apresentam distribuição ampla pelas florestas estacionais e/ou ombrófilas neotropicais, 12 ocorrem preferencialmente nas florestas estacionais e/ou ombrófilas da província Atlântica, 17 são mais freqüentes nas savanas-estépicas florestadas e/ou arborizadas da província das Caatingas, seis espécies ocorrem nas savanas florestadas da província dos Cerrados e seis espécies ocorrem simultaneamente nas Caatingas e nos Cerrados. Para seis espécies não foi determinada a área de ocorrência nem o habitat (Tab. 2).

Estrutura da Mata do Olho d'Água em Moda 1 - Os 540 indivíduos vivos amostrados em Moda 1 pertencem a 50 espécies e apresentam distância média indivíduo-ponto de $2,51 \mathrm{~m}$, o que corresponde a uma densidade total de 1.587 indivíduo.ha $^{-1}$. A área basal total de $5,40 \mathrm{~m}^{2}$ foi amostrada para os indivíduos vivos e equivale a $15,88 \mathrm{~m}^{2} \cdot \mathrm{ha}^{-1}$. A distribuição de frequiência das alturas das árvores vivas indica maior concentração de indivíduos $(21,8 \%)$ entre 5 e 5,9m (Fig. 1). A maior altura estimada é de $14,5 \mathrm{~m}$ para um indivíduo de Tabebuia impetiginosa.

A distribuição de frequiência diamétrica destaca elevada proporção de indivíduos, $76,5 \%$, com diâmetro inferior a $10 \mathrm{~cm}$ e $23 \%$ com diâmetro inferior a $5 \mathrm{~cm}$ (Fig. 2). O maior diâmetro calculado tem $46,2 \mathrm{~cm}$ e 
Tabela 2. Relação de famílias e espécies arbóreas presentes na mata do Olho d’Água, Macaíba, RN com respectivos nomes populares e números de coletas de L.A. Cestaro. A ocorrência nos levantamentos M1 (Argissolo Amarelo - Moda 1) e M2 (Neossolo Flúvico Moda 2) é indicada com "x" para as espécies registradas nos quadrantes e com "o" para as espécies apenas observadas na área. O habitat preferencial é indicado pelos números: 1 - ampla distribuição, 2 - província Atlântica, 3 - província das Caatingas, 4 - província dos Cerrados, 5 - província das Caatingas e dos Cerrados (ver detalhes em Material e Métodos).

\begin{tabular}{lcccc}
\hline Família/Espécie & Nome popular & N. de coleta & Ocorrência & Hábitat \\
& & M1 & M2 \\
\hline
\end{tabular}

\section{ANACARDIACEAE}

Anacardium occidentale $\mathrm{L}$.

Myracrodruon urundeuva Fr. All. Spondias mombin L.

ARECACEAE

Syagrus oleracea (Mart.) Becc.

BIGNONIACEAE

Jacaranda duckei Vattimo

Tabebuia impetiginosa (Mart. ex DC.) Standl.

Tabebuia roseo-alba (Ridl.) Sandw.

BOMBACACEAE

Ceiba glaziovii (Kuntze) K. Schum.

BURSERACEAE

Commiphora leptophloeos (Mart.) J.B. Gillett.

Protium heptaphyllum March.

CACTACEAE

Brasiliopuntia brasiliensis (Willd.) A. Berger

Cereus jamacaru DC.

Pilosocereus pachycladus F. Ritter

CAPPARACEAE

Capparis flexuosa (L.) L.

Capparis jacobinae Moric. ex Eichl.

CELASTRACEAE

Maytenus erythroxylon Reiss.

COCHLOSPERMACEAE

Cochlospermum vitifolium Spreng.

COMBRETACEAE

Buchenavia capitata Eichl.

ERYTHROXYLACEAE

Erythroxylum revolutum Mart.

EUPHORBIACEAE

Croton sonderianus Müll. Arg.

Pera sp.

cajueiro
aroeira
cajarana
catolé
caroba
pau-d'arco-roxo
peroba
barriguda
imburana-de-espinho
amescla-de-cheiro
cumbeba
mandacaru
facheiro-azul
feijão-bravo
icó-preto
bom-nome
algodão-do-mato
mirindiba
fruta-de-juriti
estralador

$\begin{array}{llll}01-064 & - & \mathrm{x} & 2 \\ 99-276 & \mathrm{x} & \mathrm{x} & 5 \\ 01-027 & \mathrm{x} & - & \\ & & & \end{array}$

LEGUMINOSAE

Acacia glomerosa Benth.

Anadenanthera colubrina (Vell.) Brenan

Apuleia leiocarpa J.F. Macbr.

Bauhinia cheilantha D. Dietr.

Caesalpinia ferrea Mart.

Caesalpinia gardneriana Benth.

Calliandra sessilis Benth.

Chamaecrista ensiformis (Vell.) H.S. Irwin \& Barneby

Copaifera cearensis Huber ex Ducke

Mimosa tenuiflora (Willd.) Poir.

Mimosa sp.

Piptadenia moniliformis Benth.

Piptadenia stipulacea (Benth.) Ducke

Zollernia latifolia Benth.

FLACOURTIACEAE

Casearia commersoniana Cambess.

Casearia decandra Jacq.

mercador

angico

jitaí

mororó

jucá

catingueira

barba-de-soim

pau-ferro

pau-d'óleo

jurema-preta

jurema-branca

catanduba

espinho-de-cabra

coração-de-negro

café-bravo

assa-peixe

01-062 - 0

$\begin{array}{cccc}99-171 & \mathrm{x} & \mathrm{x} & 2\end{array}$

97-149 $\quad \mathrm{x} \quad \mathrm{x} \quad 1$

99-251 $\quad x \quad x \quad 4$

$\begin{array}{llll}99-275 & \mathrm{x} & - & 3\end{array}$

01-048 $\quad x \quad x \quad 3$

99-208 - $\quad$ o

01-050 x - $\quad 3$

01-056 $\quad x \quad x \quad 5$

01-057 - $\quad x \quad 3$

99-076 $\quad x \quad$ - 3

01-060 $\quad x \quad x \quad 3$

99-011 $\quad$ x

$\begin{array}{llll}99-200 \quad \mathrm{x} & \mathrm{x} & 1\end{array}$

99-190 - $\quad$ o

01-038 -

$\begin{array}{llll}00-013 & \mathrm{x} & \mathrm{x} & 3\end{array}$

01-059 $\quad \mathrm{x} \quad \mathrm{x}$ -

$\begin{array}{llll}00-021 & \mathrm{x} & \mathrm{x} & 3\end{array}$

01-051 $\quad 0 \quad$ - 11

$\begin{array}{llll}99-021 & \mathrm{x} & - & 1 \\ 0 & \mathrm{x} & \mathrm{x} & 3\end{array}$

00-043 $\quad x \quad x \quad 3$

$\begin{array}{llll}99-210 & \mathrm{x} & \mathrm{x} & 3\end{array}$

01-053 $\quad x \quad x \quad 3$

01-030 $\quad \mathrm{x} \quad \mathrm{O} \quad 5$

99-183 $\mathrm{x} \quad \mathrm{x} \quad 2$

01-063 $\mathrm{x} \quad \mathrm{x} \quad 2$

01-055 - $\quad x \quad 3$

$\begin{array}{cccc}- & \mathrm{x} & \mathrm{x} & 3\end{array}$

96-013 $\mathrm{x} \quad \mathrm{x} \quad 5$

00-039 $\mathrm{x} \quad \mathrm{x} \quad 3$

01-066 $\quad$ o $\quad-\quad 2$

$\begin{array}{llll}99-088 & \mathrm{x} & \mathrm{x} & 1\end{array}$

01-052 $\begin{array}{llll}\mathrm{X} & - & 1\end{array}$

continua 
Tabela 2 (continuação)

\begin{tabular}{|c|c|c|c|c|c|}
\hline \multirow[t]{2}{*}{ Família/Espécie } & \multirow[t]{2}{*}{ Nome popular } & \multirow[t]{2}{*}{ N. de coleta } & \multicolumn{2}{|c|}{ Ocorrência } & \multirow[t]{2}{*}{ Habitat } \\
\hline & & & M1 & M2 & \\
\hline Casearia sylvestris $\mathrm{Sw}$. & ramo-de-carne & 00-022 & $\mathrm{x}$ & $\mathrm{x}$ & 1 \\
\hline Xylosma ciliatifolium Eichl. & espinho-de-agulha & $01-054$ & - & $\mathrm{x}$ & 1 \\
\hline \multicolumn{6}{|l|}{ LOGANIACEAE } \\
\hline Strychnos parvifolia DC. & carrasco-preto & 00-042 & $\mathrm{x}$ & $\mathrm{x}$ & 5 \\
\hline \multicolumn{6}{|l|}{ MALPIGHIACEAE } \\
\hline Byrsonima gardnerana Juss. & murici-pitanga & 99-006 & $\mathrm{x}$ & $\mathrm{x}$ & 4 \\
\hline \multicolumn{6}{|l|}{ MYRTACEAE } \\
\hline Campomanesia aromatica Griseb. & guabiraba-de-rama & $99-262$ & $\mathrm{x}$ & $\mathrm{x}$ & 1 \\
\hline Campomanesia dichotoma (Berg) Mattos & guabiraba-de-pau & $00-027$ & $\mathrm{x}$ & - & 2 \\
\hline Eugenia lucescens Niedenzu & - & $99-218$ & $\mathrm{x}$ & $\mathrm{x}$ & - \\
\hline Eugenia sp. 2 & ubaia-azeda & $99-259$ & $\mathrm{x}$ & - & - \\
\hline Eugenia sp. 3 & - & $99-102$ & $\mathrm{x}$ & $\mathrm{x}$ & - \\
\hline Eugenia sp. 4 & - & $01-017$ & $\mathrm{x}$ & - & - \\
\hline Myrcia multiflora DC. & arrebenta-boi & $01-021$ & $\mathrm{x}$ & $\mathrm{x}$ & 4 \\
\hline Myrcia aff. guianensis DC. & pau-mulato & $00-024$ & $\mathrm{x}$ & - & 1 \\
\hline Psidium oligospermum Mart. & araçá-de-jacú & $99-182$ & $\mathrm{x}$ & - & 2 \\
\hline \multicolumn{6}{|l|}{ NYCTAGINACEAE } \\
\hline Guapira laxa (Netto) Furlan & joão-mole & 01-049 & $\mathrm{x}$ & $\mathrm{x}$ & 5 \\
\hline \multicolumn{6}{|l|}{ OLACACEAE } \\
\hline Ximenia americana $\mathrm{L}$. & ameixa & $99-242$ & $\mathrm{x}$ & - & 1 \\
\hline \multicolumn{6}{|l|}{ OPILIACEAE } \\
\hline Agonandra brasiliensis Benth. \& Hook. & pau-marfim & $01-034$ & o & - & 1 \\
\hline \multicolumn{6}{|l|}{ POLYGONACEAE } \\
\hline Coccoloba alnifolia Casar. & cauaçu & $99-027$ & $\mathrm{x}$ & - & 2 \\
\hline \multicolumn{6}{|l|}{ RHAMNACEAE } \\
\hline Zizyphus joazeiro Mart. & juareiro & 99-034 & $\mathrm{x}$ & $\mathrm{x}$ & 3 \\
\hline \multicolumn{6}{|l|}{ RUBIACEAE } \\
\hline Alibertia sessilis K. Schum. & canela-de-veado & $99-240$ & o & o & 1 \\
\hline Alibertia sp. & vajucá & $01-039$ & - & $\mathrm{x}$ & - \\
\hline Alseis pickelii Pilger \& Schmale & pau-candeia & $99-029$ & $\mathrm{x}$ & - & 2 \\
\hline Guettarda platypoda DC. & angélica & $96-049$ & $\mathrm{x}$ & $\mathrm{x}$ & 4 \\
\hline Tocoyena selloana K. Schum. & jenipapo-bravo & $99-090$ & o & $\mathrm{x}$ & 4 \\
\hline \multicolumn{6}{|l|}{ RUTACEAE } \\
\hline Zanthoxylum syncarpum Tul. & limãozinho & $99-155$ & $\mathrm{x}$ & $\mathrm{x}$ & 1 \\
\hline \multicolumn{6}{|l|}{ SAPINDACEAE } \\
\hline Allophylus edulis (A. St.-Hil.) Niederl. & cumichá-branco & 01-018 & $\mathrm{x}$ & $\mathrm{x}$ & 1 \\
\hline \multicolumn{6}{|l|}{ SAPOTACEAE } \\
\hline Sideroxylon obtusifolium (Roem. \& Schult.) T.D. Penn. & quixabeira & $01-040$ & - & $\mathrm{x}$ & 1 \\
\hline STERCULIACEAE & & & & & \\
\hline Helicteres heptandra L.B. Smith & guachumba-vermelha & $97-093$ & $\mathrm{x}$ & - & 3 \\
\hline \multicolumn{6}{|l|}{ TILIACEAE } \\
\hline Luehea ochrophylla Mart. & açoita-cavalo & $97-100$ & o & - & 2 \\
\hline \multicolumn{6}{|l|}{ ULMACEAE } \\
\hline Trema micrantha (L.) Blume & tamanqueira & $99-128$ & $\mathrm{x}$ & - & 1 \\
\hline
\end{tabular}

pertence a um indivíduo de Ceiba glaziovii. A elevada proporção de indivíduos com troncos finos pode sugerir a presença marcante de regenerantes, entretanto, 14 espécies não apresentam indivíduos com DAP $\geq 5 \mathrm{~cm}$ (Brasiliopuntia brasiliensis, Calliandra sessilis, Capparis jacobinae, Casearia commersoniana, Casearia decandra, Casearia sylvestris, Copaifera cearensis, Croton sonderianus, Eugenia lucescens,
Eugenia sp. 4, Helicteres heptandra, Maytenus erythroxylon, Strychnos parvifolia e Trema micrantha). Trinta espécies ocorrem apenas com DAP $<10 \mathrm{~cm}$, o que equivale a $60 \%$ das espécies registradas nos quadrantes.

Piptadenia moniliformis é a espécie que apresenta os maiores valor de importância (VI) e valor de cobertura (VC) em função do maior número de 
indivíduos amostrados e sobretudo do maior número de pontos em que ocorreu (Tab. 3). A maior área basal foi encontrada para Tabebuia impetiginosa. As outras quatro espécies que apresentam maiores VI e VC, em ordem decrescente, são Tabebuia impetiginosa, Chamaecrista ensiformis, Guapira laxa e Alseis pickelii.

A diversidade arbórea $\mathrm{H}^{\prime}$ resultou em 3,19 e a equabilidade J', em 0,79 .

Foram registradas nos quadrantes 29 árvores mortas em pé, com área basal de $0,69 \mathrm{~m}^{2} \cdot \mathrm{ha}^{-1}$. Esses valores correspondem a $5,37 \%$ dos indivíduos amostrados e a $4,25 \%$ da área basal total no levantamento em que a categoria mortas foi incluída. Se as árvores mortas fossem consideradas no cálculo do VI obteriam o sexto maior valor.

Estrutura da Mata do Olho d'Água em Moda 2 Foram amostrados 260 indivíduos vivos pertencentes a 40 espécies, com distância média indivíduo-ponto de 2,28m, o que corresponde a densidade total de 1.924 indivíduo.ha ${ }^{-1}$. A área basal amostrada para os indivíduos vivos totalizou $2,14 \mathrm{~m}^{2}$ e equivale a $15,86 \mathrm{~m}^{2} \cdot \mathrm{ha}^{-1}$. A distribuição das freqüências de altura das árvores vivas indica maior concentração de indivíduos, 27,8\%, entre 6e 6,9m (Fig. 1). A maior altura, $14 \mathrm{~m}$, foi estimada para um indivíduo de Piptadenia moniliformis.

A distribuição das freqüências diamétricas das árvores destaca elevada percentagem de indivíduos, $80 \%$, com diâmetro inferior a $10 \mathrm{~cm}$ (Fig. 2). O maior diâmetro calculado $(32,8 \mathrm{~cm})$ pertence a um indivíduo de Piptadenia moniliformis. Dez espécies ocorreram apenas com DAP $<5 \mathrm{~cm}$ (Alibertia sp., Bauhinia

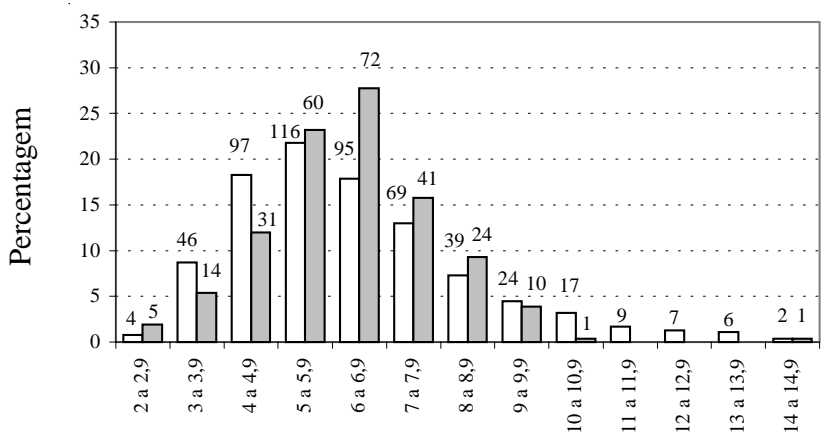

Intervalos de altura (m)

Figura 1. Distribuição relativa, por intervalo de altura, das árvores em pé amostradas na mata do Olho d’Água sobre Argissolo Amarelo (Moda 1) e sobre Neossolo Flúvico (Moda 2), no município de Macaíba, RN. Os números sobre as barras referem-se à quantidade de indivíduos amostrados em cada intervalo. $\square$ Moda 1 . Moda 2 . cheilantha, Byrsonima gardnerana, Capparis jacobinae, Casearia commersoniana, Copaifera cearensis, Erythroxylum revolutum, Eugenia sp. 3, Strycnos parvifolia e Tocoyena selloana) e 21 espécies, apenas com DAP $<10 \mathrm{~cm}$, o que equivale a $52 \%$ do total de espécies registradas nos quadrantes.

Piptadenia moniliformis é a espécie que apresenta os maiores valor de importância (VI) e valor de cobertura (VC), visto que ocorreu com o maior número de indivíduos no maior número de pontos (Tab. 4). Chamaecrista ensiformis ocupa o segundo lugar em VI e em VC, embora apresente a maior área basal dentre as espécies. As outras três espécies em ordem decrescente de VI e VC são Caesalpinia gardneriana, Guapira laxa e Croton sonderianus.

A diversidade arbórea H' resultou em 3,26 e a equabilidade J', em 0,86 .

Foram registradas nos quadrantes oito árvores mortas em pé, com área basal de $0,21 \mathrm{~m}^{2} \cdot$ ha $^{-1}$. Esses valores correspondem a 3,08\% dos indivíduos amostrados e a $1,28 \%$ da área basal total no levantamento em que a categoria mortas foi incluída. Se as árvores mortas fossem consideradas no cálculo do VI, obteriam o décimo terceiro maior valor.

Moda $1 \times$ Moda 2 - Os valores dos índices de similaridade $\mathrm{S}_{\mathrm{S}}$ e $\mathrm{S}_{\mathrm{C}}$, obtidos da comparação entre Moda 1 e Moda 2, são respectivamente 0,69 e 0,53. Algumas espécies ocorreram apenas ou em quantidade muito maior em Moda 1, podendo ser citadas entre as mais abundantes: Tabebuia impetiginosa, Alseis pickelii, Byrsonima gardnerana, Spondias mombin, Pera sp., Eugenia sp. 2, Ceiba glaziovii, Myrcia aff.

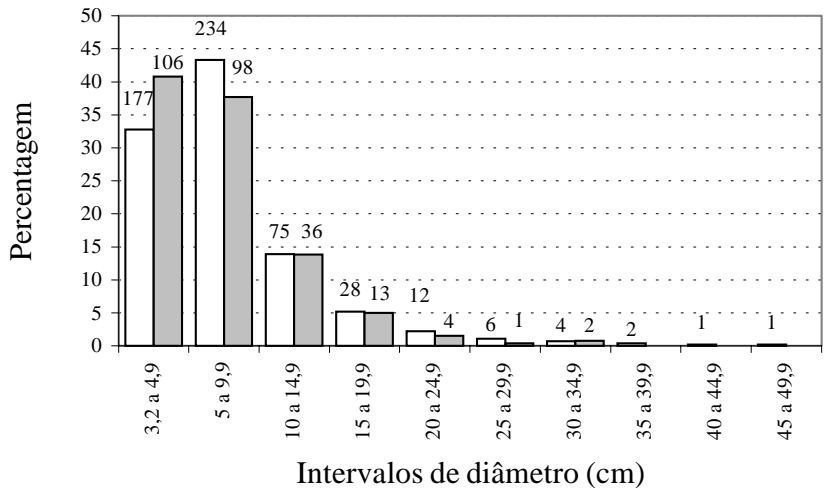

Figura 2. Distribuição relativa, por intervalo de diâmetro, das árvores com diâmetro a $1,3 \mathrm{~m}$ de altura igual ou superior a $3,2 \mathrm{~cm}$ amostrados na mata do Olho d'Água sobre Argissolo Amarelo (Moda 1) e sobre Neossolo Flúvico (Moda 2), no município de Macaíba, RN. Os números sobre as barras indicam a quantidade de indivíduos amostrados em cada intervalo. $\square$ Moda 1. $\square$ Moda 2. 
Tabela 3. Relação das espécies arbóreas amostradas na mata do Olho d’Água, Macaíba, RN, sobre Argissolo Amarelo e seus respectivos parâmetros fitossociológicos ( $\mathrm{Np}=$ número de pontos de presença; $\mathrm{Ni}=$ número de indivíduos amostrados; $\mathrm{AB}=$ área basal; $\mathrm{FR}=$ frequiência relativa; $\mathrm{DR}=$ densidade relativa; $\mathrm{DoR}=$ dominância relativa; $\mathrm{VI}=$ valor de importância relativo; $\mathrm{VC}=$ valor de cobertura relativo).

\begin{tabular}{|c|c|c|c|c|c|c|c|c|}
\hline Espécie & $\mathrm{Np}$ & $\mathrm{Ni}$ & $\begin{array}{l}\text { AB } \\
\left(m^{2}\right)\end{array}$ & $\begin{array}{l}\text { FR } \\
(\%)\end{array}$ & $\begin{array}{l}\text { DR } \\
(\%)\end{array}$ & $\begin{array}{c}\text { DoR } \\
(\%)\end{array}$ & $\begin{array}{l}\text { VI } \\
(\%)\end{array}$ & $\begin{array}{l}\mathrm{VC} \\
(\%)\end{array}$ \\
\hline 1. Piptadenia moniliformis & 48 & 61 & 0,7583 & 10,74 & 11,30 & 14,04 & 12,023 & 12,661 \\
\hline 2. Tabebuia impetiginosa & 24 & 37 & 0,9175 & 5,37 & 6,85 & 16,99 & 9,734 & 11,911 \\
\hline 3. Chamaecrista ensiformis & 38 & 50 & 0,5639 & 8,50 & 9,26 & 10,44 & 9,397 & 9,843 \\
\hline 4. Guapira laxa & 43 & 52 & 0,4461 & 9,62 & 9,63 & 8,26 & 9,167 & 8,938 \\
\hline 5. Alseis pickelii & 34 & 48 & 0,3900 & 7,61 & 8,89 & 7,22 & 7,904 & 8,049 \\
\hline 6. Byrsonima gardnerana & 21 & 27 & 0,1935 & 4,70 & 5,00 & 3,58 & 4,425 & 4,287 \\
\hline 7. Spondias mombin & 10 & 13 & 0,4438 & 2,24 & 2,41 & 8,21 & 4,285 & 5,306 \\
\hline 8. Acacia glomerosa & 25 & 30 & 0,0774 & 5,59 & 5,56 & 1,43 & 4,192 & 3,492 \\
\hline 9. Pera sp. & 21 & 22 & 0,1192 & 4,70 & 4,07 & 2,21 & 3,659 & 3,138 \\
\hline 10. Bauhinia cheilantha & 17 & 22 & 0,0970 & 3,80 & 4,07 & 1,80 & 3,222 & 2,933 \\
\hline 11. Zanthoxylum syncarpum & 15 & 17 & 0,1402 & 3,36 & 3,15 & 2,60 & 3,036 & 2,873 \\
\hline 12. Caesalpinia gardneriana & 13 & 15 & 0,1166 & 2,91 & 2,78 & 2,16 & 2,616 & 2,468 \\
\hline 13. Eugenia sp. 2 & 14 & 16 & 0,0838 & 3,13 & 2,96 & 1,55 & 2,546 & 2,253 \\
\hline 14. Ceiba glaziovii & 2 & 3 & 0,3298 & 0,45 & 0,56 & 6,11 & 2,373 & 3,333 \\
\hline 15. Caesalpinia ferrea & 13 & 13 & 0,0528 & 2,91 & 2,41 & 0,98 & 2,099 & 1,694 \\
\hline 16. Piptadenia stipulacea & 11 & 13 & 0,0223 & 2,46 & 2,41 & 0,41 & 1,759 & 1,409 \\
\hline 17. Tabebuia roseo-alba & 9 & 10 & 0,0625 & 2,01 & 1,85 & 1,16 & 1,673 & 1,504 \\
\hline 18. Commiphora leptophloeos & 8 & 8 & 0,0914 & 1,79 & 1,48 & 1,69 & 1,653 & 1,584 \\
\hline 19. Myrcia aff. guianensis & 9 & 9 & 0,0626 & 2,01 & 1,67 & 1,16 & 1,613 & 1,414 \\
\hline 20. Eugenia sp. 3 & 6 & 6 & 0,0358 & 1,34 & 1,11 & 0,66 & 1,036 & 0,884 \\
\hline 21. Cereus jamacaru & 3 & 3 & 0,0979 & 0,67 & 0,56 & 1,81 & 1,013 & 1,184 \\
\hline 22. Capparis flexuosa & 6 & 7 & 0,0167 & 1,34 & 1,30 & 0,31 & 0,983 & 0,804 \\
\hline 23. Campomanesia aromatica & 6 & 6 & 0,0236 & 1,34 & 1,11 & 0,44 & 0,963 & 0,774 \\
\hline 24. Strycnos parvifolia & 5 & 5 & 0,0100 & 1,12 & 0,93 & 0,19 & 0,746 & 0,560 \\
\hline 25. Allophylus edulis & 4 & 4 & 0,0184 & 0,89 & 0,74 & 0,34 & 0,656 & 0,540 \\
\hline 26. Mimosa sp. & 1 & 1 & 0,0734 & 0,22 & 0,19 & 1,36 & 0,590 & 0,774 \\
\hline 27. Jacaranda duckei & 4 & 4 & 0,0064 & 0,89 & 0,74 & 0,12 & 0,583 & 0,430 \\
\hline 28. Apuleia leiocarpa & 3 & 4 & 0,0119 & 0,67 & 0,74 & 0,22 & 0,543 & 0,480 \\
\hline 29. Coccoloba alnifolia & 3 & 3 & 0,0172 & 0,67 & 0,56 & 0,32 & 0,517 & 0,440 \\
\hline 30. Campomanesia dichotoma & 3 & 3 & 0,0102 & 0,67 & 0,56 & 0,19 & 0,473 & 0,375 \\
\hline 31. Psidium oligospermum & 3 & 3 & 0,0047 & 0,67 & 0,56 & 0,09 & 0,440 & 0,325 \\
\hline 32. Calliandra sessilis & 3 & 3 & 0,0044 & 0,67 & 0,56 & 0,08 & 0,437 & 0,320 \\
\hline 33. Zizyphus joazeiro & 1 & 1 & 0,0392 & 0,22 & 0,19 & 0,73 & 0,380 & 0,460 \\
\hline 34. Cochlospermum vitifolium & 2 & 2 & 0,0076 & 0,45 & 0,37 & 0,14 & 0,320 & 0,255 \\
\hline 35. Myrcia multiflora & 2 & 2 & 0,0058 & 0,45 & 0,37 & 0,11 & 0,310 & 0,240 \\
\hline 36. Guetarda platypoda & 2 & 2 & 0,0051 & 0,45 & 0,37 & 0,09 & 0,303 & 0,230 \\
\hline 37. Eugenia sp. 4 & 2 & 2 & 0,0027 & 0,45 & 0,37 & 0,05 & 0,290 & 0,210 \\
\hline 38. Ximenia americana & 1 & 1 & 0,0176 & 0,22 & 0,19 & 0,33 & 0,247 & 0,260 \\
\hline 39. Myracrodruon urundeuva & 1 & 1 & 0,0042 & 0,22 & 0,19 & 0,08 & 0,163 & 0,135 \\
\hline 40. Casearia commersoniana & 1 & 1 & 0,0037 & 0,22 & 0,19 & 0,07 & 0,160 & 0,130 \\
\hline 41. Maytenus erythroxylon & 1 & 1 & 0,0033 & 0,22 & 0,19 & 0,06 & 0,157 & 0,125 \\
\hline 42. Capparis jacobinae & 1 & 1 & 0,0031 & 0,22 & 0,19 & 0,06 & 0,157 & 0,125 \\
\hline 43. Copaifera cearensis & 1 & 1 & 0,0019 & 0,22 & 0,19 & 0,04 & 0,150 & 0,115 \\
\hline 44. Croton sonderianus & 1 & 1 & 0,0017 & 0,22 & 0,19 & 0,03 & 0,147 & 0,110 \\
\hline 45. Brasiliopuntia brasiliensis & 1 & 1 & 0,0013 & 0,22 & 0,19 & 0,02 & 0,143 & 0,105 \\
\hline 46. Helicteres heptandra & 1 & 1 & 0,0013 & 0,22 & 0,19 & 0,02 & 0,143 & 0,105 \\
\hline 47. Casearia decandra & 1 & 1 & 0,0012 & 0,22 & 0,19 & 0,02 & 0,143 & 0,105 \\
\hline 48. Eugenia lucescens & 1 & 1 & 0,0010 & 0,22 & 0,19 & 0,02 & 0,143 & 0,105 \\
\hline 49. Trema micrantha & 1 & 1 & 0,0010 & 0,22 & 0,19 & 0,02 & 0,143 & 0,105 \\
\hline 50. Casearia sylvestris & 1 & 1 & 0,0009 & 0,22 & 0,19 & 0,02 & 0,143 & 0,105 \\
\hline Total da amostra & 135 & 540 & 5,4019 & 100,00 & 100,00 & 100,00 & 100,00 & 100,00 \\
\hline
\end{tabular}


Tabela 4. Relação das espécies arbóreas amostradas na mata do Olho d’Água, Macaíba, RN, sobre Neossolo Flúvico e seus respectivos parâmetros fitossociológicos $(\mathrm{Np}=$ número de pontos de presença; $\mathrm{Ni}=$ número de indivíduos amostrados; $\mathrm{AB}=$ área basal; $\mathrm{FR}=$ frequiência relativa; DR = densidade relativa; DoR = dominância relativa; $\mathrm{VI}=$ valor de importância relativo; $\mathrm{VC}=$ valor de cobertura relativo).

\begin{tabular}{|c|c|c|c|c|c|c|c|c|}
\hline Espécie & $\mathrm{Np}$ & $\mathrm{Ni}$ & $\begin{array}{l}\mathrm{AB} \\
\left(\mathrm{m}^{2}\right)\end{array}$ & $\begin{array}{l}\text { FR } \\
(\%)\end{array}$ & $\begin{array}{l}\text { DR } \\
(\%)\end{array}$ & $\begin{array}{c}\text { DoR } \\
(\%)\end{array}$ & $\begin{array}{l}\text { VI } \\
(\%)\end{array}$ & $\begin{array}{l}\mathrm{VC} \\
(\%)\end{array}$ \\
\hline 1. Piptadenia moniliformis & 15 & 25 & 0,3143 & 7,18 & 9,62 & 14,67 & 10,49 & 12,15 \\
\hline 2. Chamaecrista ensiformis & 13 & 16 & 0,3661 & 6,22 & 6,15 & 17,08 & 9,82 & 11,62 \\
\hline 3. Caesalpinia gardneriana & 12 & 16 & 0,2140 & 5,74 & 6,15 & 9,98 & 7,29 & 8,07 \\
\hline 4. Guapira laxa & 12 & 15 & 0,1467 & 5,74 & 5,77 & 6,84 & 6,12 & 6,31 \\
\hline 5. Croton sonderianus & 15 & 22 & 0,0515 & 7,18 & 8,46 & 2,40 & 6,01 & 5,43 \\
\hline 6. Zanthoxylum syncarpum & 16 & 19 & 0,0548 & 7,66 & 7,31 & 2,56 & 5,84 & 4,94 \\
\hline 7. Caesalpinia ferrea & 13 & 13 & 0,1242 & 6,22 & 5,00 & 5,79 & 5,67 & 5,40 \\
\hline 8. Acacia glomerosa & 14 & 16 & 0,0612 & 6,70 & 6,15 & 2,85 & 5,23 & 4,50 \\
\hline 9. Campomanesia aromatica & 9 & 15 & 0,0708 & 4,31 & 5,77 & 3,30 & 4,46 & 4,54 \\
\hline 10. Mimosa tenuiflora & 7 & 11 & 0,1056 & 3,35 & 4,23 & 4,93 & 4,17 & 4,58 \\
\hline 11. Commiphora leptophloeos & 6 & 6 & 0,1364 & 2,87 & 2,31 & 6,37 & 3,85 & 4,34 \\
\hline 12. Pilosocereus pachycladus & 4 & 4 & 0,1096 & 1,91 & 1,54 & 5,11 & 2,85 & 3,33 \\
\hline 13. Cereus jamacaru & 4 & 4 & 0,0730 & 1,91 & 1,54 & 3,41 & 2,29 & 2,48 \\
\hline 14. Bauhinia cheilantha & 6 & 7 & 0,0084 & 2,87 & 2,69 & 0,39 & 1,98 & 1,54 \\
\hline 15. Eugenia lucescens & 4 & 5 & 0,0439 & 1,91 & 1,92 & 2,05 & 1,96 & 1,99 \\
\hline 16. Zizyphus joazeiro & 5 & 5 & 0,0200 & 2,39 & 1,92 & 0,93 & 1,75 & 1,42 \\
\hline 17. Piptadenia stipulacea & 5 & 6 & 0,0101 & 2,39 & 2,31 & 0,47 & 1,72 & 1,39 \\
\hline 18. Casearia sylvestris & 5 & 5 & 0,0135 & 2,39 & 1,92 & 0,63 & 1,65 & 1,28 \\
\hline 19. Myracrodruon urundeuva & 3 & 3 & 0,0384 & 1,44 & 1,15 & 1,79 & 1,46 & 1,47 \\
\hline 20. Pera sp. & 4 & 4 & 0,0189 & 1,91 & 1,54 & 0,88 & 1,44 & 1,21 \\
\hline 21. Xylosma ciliatifolium & 4 & 4 & 0,0164 & 1,91 & 1,54 & 0,77 & 1,41 & 1,16 \\
\hline 22. Jacaranda duckei & 3 & 5 & 0,0179 & 1,44 & 1,92 & 0,84 & 1,40 & 1,38 \\
\hline 23. Mimosa sp. & 4 & 4 & 0,0124 & 1,91 & 1,54 & 0,58 & 1,34 & 1,06 \\
\hline 24. Cochlospermum vitifolium & 3 & 3 & 0,0240 & 1,44 & 1,15 & 1,12 & 1,24 & 1,14 \\
\hline 25. Guetarda platypoda & 3 & 4 & 0,0067 & 1,44 & 1,54 & 0,31 & 1,10 & 0,92 \\
\hline 26. Anacardium occidentale & 1 & 2 & 0,0198 & 0,48 & 0,77 & 0,92 & 0,72 & 0,84 \\
\hline 27. Allophylus edulis & 2 & 2 & 0,0093 & 0,96 & 0,77 & 0,43 & 0,72 & 0,60 \\
\hline 28. Tabebuia roseo-alba & 2 & 2 & 0,0083 & 0,96 & 0,77 & 0,39 & 0,71 & 0,58 \\
\hline 29. Byrsonima gardnerana & 1 & 3 & 0,0046 & 0,48 & 1,15 & 0,22 & 0,62 & 0,68 \\
\hline 30. Erythroxylum revolutum & 2 & 2 & 0,0019 & 0,96 & 0,77 & 0,09 & 0,61 & 0,43 \\
\hline 31. Strycnos parvifolia & 2 & 2 & 0,0018 & 0,96 & 0,77 & 0,08 & 0,60 & 0,42 \\
\hline 32. Copaifera cearensis & 2 & 2 & 0,0016 & 0,96 & 0,77 & 0,08 & 0,60 & 0,42 \\
\hline 33. Sideroxylon obtusifolium & 1 & 1 & 0,0199 & 0,48 & 0,38 & 0,93 & 0,60 & 0,66 \\
\hline 34. Myrcia multiflora & 1 & 1 & 0,0067 & 0,48 & 0,38 & 0,31 & 0,39 & 0,34 \\
\hline 35. Tabebuia impetiginosa & 1 & 1 & 0,0041 & 0,48 & 0,38 & 0,19 & 0,35 & 0,28 \\
\hline 36. Capparis jacobinae & 1 & 1 & 0,0028 & 0,48 & 0,38 & 0,13 & 0,33 & 0,26 \\
\hline 37. Tocoyena selloana & 1 & 1 & 0,0010 & 0,48 & 0,38 & 0,05 & 0,30 & 0,22 \\
\hline 38. Casearia commersoniana & 1 & 1 & 0,0009 & 0,48 & 0,38 & 0,04 & 0,30 & 0,21 \\
\hline 39. Alibertia sp. & 1 & 1 & 0,0009 & 0,48 & 0,38 & 0,04 & 0,30 & 0,21 \\
\hline 40. Eugenia sp. 3 & 1 & 1 & 0,0008 & 0,48 & 0,38 & 0,04 & 0,30 & 0,21 \\
\hline Total da amostra & 65 & 260 & 2,1432 & 100,00 & 100,00 & 100,00 & 100,00 & 100,00 \\
\hline
\end{tabular}

guianensis, Tabebuia roseo-alba e Capparis flexuosa, enquanto Caesalpinia gardneriana, Croton sonderianus, Zanthoxylum syncarpum, Caesalpinia ferrea, Campomanesia aromatica, Mimosa tenuiflora, Eugenia lucescens e Casearia sylvestris se destacaram em Moda 2.

As distribuições de freqüência das alturas são estatisticamente iguais $(p \geq 0,05)$ para Moda 1 e Moda 2
(Fig. 1). A análise visual das distribuições revela, entretanto, distribuição mais equilibrada para as árvores de Moda 1, com maior concentração (58\%) no intervalo entre 4 a $6,9 \mathrm{~m}$, enquanto em Moda 2 a maior concentração de indivíduos (51\%) ocorre entre 5 e $6,9 \mathrm{~m}$, com poucos ultrapassando a altura de $10 \mathrm{~m}$. Moda 2 parece apresentar maior uniformidade de altura para o conjunto de árvores, com dossel mais alto, em 
torno de 6 a 8m, com poucas árvores emergentes de Piptadenia moniliformis. Em Moda 1 o dossel é pouco mais baixo e aberto, com altura entre 5 e $7 \mathrm{~m}$, enquanto a diversidade e a altura das emergentes são maiores, envolvendo indivíduos de Piptadenia moniliformis, Tabebuia roseo-alba, Guapira laxa, Caesalpinia gardneriana e, principalmente num setor da mata, Tabebuia impetiginosa e Ceiba glaziovii.

As estruturas de diâmetro do caule das duas áreas são estatisticamente iguais $(\mathrm{p} \geq 0,05)$ (Fig. 2). A proporção de árvores com diâmetro acima de $15 \mathrm{~cm}$, entretanto, é ligeiramente maior em Moda 1 (9,6\%), do que em Moda 2 (7,3\%). Em Moda 2 também não foram registrados indivíduos com diâmetro acima de $35 \mathrm{~cm}$. Esses dados apontam para maior uniformidade dos diâmetros de caule em Moda 2.

\section{Discussão}

Os solos originados dos sedimentos do grupo Barreiras geralmente apresentam acidez elevada, concentração de alumínio de média a alta e são pobres em bases trocáveis, portanto, com fertilidade de baixa a muito baixa (Ranzani et al. 1964; Jacomine et al. 1971; Souza et al. 1981). Os solos da área estudada, apesar de originados desses sedimentos, são menos pobres, provavelmente devido à menor pluviosidade a que estão submetidos, diminuindo a exportação de materiais do sistema por lixiviação.

O Argissolo apresenta fertilidade média, em função sobretudo da alta concentração de cálcio e da baixa concentração de alumínio trocável. A maior fertilidade da camada superficial, apesar do menor teor de argila, provavelmente está relacionada com a camada de serapilheira que, embora delgada, deve apresentar matéria orgânica em quantidade suficiente para atuar na dinâmica dos nutrientes. A grande quantidade de cascalhos e calhaus na massa do solo não tem relevância nos processos químicos, entretanto, nas áreas de relevo mais inclinado, observa-se acúmulo excepcional desses seixos na superfície. Essa característica indica que o solo, sobretudo em função do relevo um tanto acidentado, é bastante suscetível à erosão e sujeito a rápida dessecação. A cobertura vegetal, interceptando as gotas de chuva e auxiliando na infiltração em detrimento do escorrimento superficial, desempenha importante papel na atenuação desses processos.

Apesar de ser solo arenoso, o Neossolo apresenta uma fertilidade relativamente alta na camada superficial. Essa fertilidade provavelmente está relacionada com os materiais transportados do Argissolo e com sua retenção pela matéria orgânica, uma vez que a baixa concentração de argila não favorece a adsorção de cátions (Wutke \& Camargo 1972). A menor concentração de alumínio na camada superficial provavelmente está relacionada com o maior teor de cálcio, o qual tem papel importante na redução da acidez, com conseqüente neutralização do alumínio trocável (Wutke 1972). A Moda 2, em relação à Moda 1 , apresenta solos mais restritivos ao desenvolvimento das plantas, em termos de fertilidade e de toxidez por alumínio; entretanto, por localizar-se na porção mais baixa do terreno e apresentar relevo mais plano, deve permanecer com água disponível no solo por mais tempo.

As espécies com diâmetro de caule relativamente delgado mostraram-se importantes na constituição tanto florística quanto estrutural de Moda. Os dados poderiam sugerir corte seletivo eliminando os indivíduos mais grossos dessas espécies, uma vez que a história recente da mata envolve exploração madeireira. As características da maioria das espécies, entretanto, são o pequeno porte e a baixa qualidade da madeira, o que não favorece a exploração. A grande quantidade de espécies com diâmetro de caule reduzido indica que a utilização de critérios de inclusão de indivíduos mais restritivos do que os adotados neste trabalho implicaria em caracterizações florística e estrutural menos precisas. Recomenda-se, portanto, a utilização do critério de inclusão aqui utilizado ( $\mathrm{PAP} \geq 10 \mathrm{~cm}$ ) para trabalhos em matas decíduas da região.

As estruturas de altura e de diâmetro do caule das árvores nos dois ambientes são bastante semelhantes. As áreas basais são praticamente idênticas, apesar da maior densidade de árvores em Moda 2. A maior uniformidade das árvores em termos de altura e de diâmetro do caule em Moda 2 provavelmente está relacionada com o adensamento das árvores e com os elevados teores de alumínio nos horizontes subsuperficiais do solo. Altas concentrações de alumínio podem interferir tanto na seleção de espécies como no desenvolvimento das plantas (Malavolta \& Kliemann 1985).

As percentagens de indivíduos mortos nas duas áreas, $5 \%$ e $3 \%$, podem ser consideradas baixas, tendo em conta o critério de inclusão abrangente utilizado no levantamento (Phillips et al. 1998). Esses valores não refletem necessariamente ausência de distúrbios, uma vez que podem indicar coleta de lenha; essa sim uma ação que pode comprometer a sustentabilidade da mata, 
pois troncos mortos têm importantes funções ecológicas nas florestas (Delaney et al. 1998).

Em Moda 1 algumas espécies tiveram certo destaque quantitativo em relação às demais. Isso não foi observado em Moda 2, onde as diferenças na distribuição dos indivíduos, do VI e do VC entre as espécies são menos acentuadas. Essas características se refletem nos índices J' e H'. Moda 2, mesmo apresentando menor riqueza de espécies, encerra maior diversidade, reflexo da distribuição menos desigual dos indivíduos entre as espécies, fato que é ressaltado pelo elevado valor de J'.

Os valores de H' obtidos para Moda $1(3,19)$ e para Moda $2(3,26)$ indicam diversidade de média a alta, segundo a classificação proposta por Soares-Filho (2000). Esses valores são semelhantes àqueles obtidos por Trindade (1991) para uma floresta semidecídua nas proximidades da cidade de Natal $(3,14)$, e por SoaresFilho (2000), para um fragmento de Floresta Decidual Montana (mata de cipó) em Cândido Sales, BA $(3,21)$.

Piptadenia moniliformis, a espécie mais abundante nas duas áreas, é heliófila, decídua, pioneira e endêmica de solos arenosos desde o Maranhão até a Bahia, principalmente nas Caatingas, mas ocasional nos Cerrados (Salgado et al. 1981; Lewis 1987; Andrade-Lima 1989; Lorenzi 1998; Ratter et al. 2000). A espécie é muito abundante nas caatingas arenosas da porção setentrional do Rio Grande do Norte (Figueiredo 1987).

A segunda espécie mais abundante na mata e bastante explorada localmente para a obtenção de estacas e mourões é Chamaecrista ensiformis. Essa espécie é particularmente freqüente nas restingas costeiras, desde o Maranhão até São Paulo, podendo ocorrer também em matas de galeria nos Cerrados, sempre em solos arenosos (Irwin \& Barneby 1977; Costa 1996). A espécie é muito abundante nas matas semidecíduas bem próximas ao litoral perto da cidade de Natal (Trindade 1991).

Ceiba glaziovii, Spondias mombin e Cereus jamacaru em Moda 1, e Commiphora leptophloeos, Pilosocereus pachycladus e Cereus jamacaru em Moda 2 distinguem-se por apresentar poucos indivíduos, sempre com diâmetro de caule maior do que para a maioria das espécies, o que pode indicar problemas de sustentabilidade para as populações. Croton sonderianus, Zanthoxylum syncarpum e Acacia glomerosa são abundantes em Moda 2 e apresentam elevada proporção de indivíduos com caules relativamente finos, o que é natural para essas espécies de porte mais reduzido.
Tabebuia impetiginosa, em Moda 1, ocorreu com número grande de indivíduos, porém com freqüência relativa baixa. É provável que a espécie apresente distribuição gregária, tendo em vista o alto valor da relação número de indivíduos por número de pontos, o maior dentre as espécies amostradas. Essa relação foi sugerida por Martins (1991) para detectar tendência à distribuição gregária em levantamentos utilizando o método dos quadrantes. De fato, Tabebuia impetiginosa ocorre preferencialmente em um setor de Moda 1, o que pode reforçar a tendência sugerida pelos dados. Em Moda 2, propensão a gregarismo foi detectado em Piptadenia moniliformis, Campomanesia aromatica, Mimosa tenuiflora e Croton sonderianus.

Os valores dos índices de similaridade $\left(S_{S}=0,69\right.$ e $S_{C}=0,53$ ), podem ser considerados altos, tendo em vista a heterogeneidade interna das comunidades vegetais, característica marcante sobretudo em florestas tropicais (Gentry 1988). Pode-se afirmar, portanto, que Moda 1 e Moda 2 apresentam elevada semelhança entre si, tanto em termos florísticos, quanto em termos da distribuição de indivíduos entre as espécies.

A grande afinidade estrutural e florística entre as áreas não impede, todavia, que as particularidades se evidenciem. Moda 1 distingue-se de Moda 2 por apresentar espécies de maior porte, como Ceiba glaziovii, Tabebuia impetiginosa, Spondias mombin e Alseis pickelii. Essas espécies ocorrem preferencialmente em matas secas, sobretudo as duas primeiras. O conjunto de espécies que compõem Moda 2 não apresentou preferência clara por um determinado habitat, contudo algumas espécies com destacada importância, como Caesalpinia gardneriana, Croton sonderianus e Mimosa tenuiflora, são típicas das Caatingas (Andrade-Lima 1989; Lewis 1998), enquanto Zanthoxylum syncarpum, no Brasil, ocorre preferencialmente na zona de transição entre as províncias Atlântica e das Caatingas (Pirani 1999).

As análises indicam, portanto, haver uma tendência em relação às espécies diferenciais, com aquelas espécies de maior porte e de maior afinidade com as matas secas ocorrendo nas porções mais elevadas do terreno (Moda 1), e aquelas de ampla distribuição pelas Caatingas ocupando as porções mais baixas do relevo (Moda 2). Essas associações provavelmente estão relacionadas com o grau de fertilidade dos solos nos dois ambientes, com as espécies mais comuns em matas secas preferindo os 
solos menos pobres em nutrientes. Fertilidade, teor de alumínio e regime hídrico dos solos possivelmente são os principais elementos a determinar as pequenas diferenças florística e estrutural da vegetação observadas entre os dois ambientes analisados.

A elevada riqueza de Leguminosae em Moda era esperada, visto ser essa família uma das mais diversificadas, não apenas nas províncias fitogeográficas Atlântica, dos Cerrados e Amazônica (OliveiraFilho \& Fontes 2000), mas também em todas as regiões tropicais com estação seca marcante (Gentry 1988, Gillespie et al. 2000), o que inclui também as Caatingas. O grande número de espécies de Myrtaceae, entretanto, pode sugerir maior afinidade da mata com a província Atlântica, onde a família é bastante diversificada (Mori et al. 1983; Oliveira-Filho \& Fontes 2000). A análise da proporção de espécies quanto aos habitats preferenciais revelou a significativa participação das espécies das Caatingas na composição arbórea de Moda, embora o número de espécies com ampla distribuição pelas florestas estacionais neotropicais seja maior. Quando os parâmetros quantitativos foram envolvidos na análise, os maiores valores foram obtidos pelo conjunto de espécies das Caatingas. A espécie mais abundante em Moda, Piptadenia moniliformis, ocorre tanto nas Caatingas quanto nos Cerrados, enquanto a segunda mais comum, Chamaecrista ensiformis, compõe a província Atlântica. A participação expressiva em Moda de espécies características de matas secas neotropicais, como Tabebuia impetiginosa, Myracrodruon urundeuva, Sideroxylon obtusifolium, Anadenanthera colubrina, Zanthoxylum syncarpum e Tabebuia roseoalba apontam para afinidade florística com essas matas, as quais regionalmente apresentam elevada conectividade florística, conforme sugerem Sarmiento (1975), Prado \& Gibbs (1993) e Prado (2000).

A classificação da vegetação envolve aspectos fisionômicos, estruturais, florísticos e ecológicos (Rizzini 1979; IBGE 1992). Fisionômica e estruturalmente, Moda apresenta como características predominantes a caducifólia, a baixa freqüência de espécies armadas, o porte arbóreo relativamente desenvolvido e um dossel não muito compacto, o que a distingue tanto da Floresta Semidecídua e da Savana-estépica Florestada (IBGE 1992) quanto da Caatinga Florestal de Eiten (1983) e da Caatinga Arbórea Espinhosa de Andrade-Lima (1981). Floristicamente, Moda apresenta um conjunto significativo de espécies neotropicais de ampla dispersão e sofre influência das províncias das Caatingas, Atlântica e dos Cerrados. Quando parâmetros quantitativos são considerados, entretanto, a influência das Caatingas é maior. Segundo Reis (1976) e Andrade-Lima (1981), a província das Caatingas é delimitada pela isoieta de $1.000 \mathrm{~mm}$ anuais; Moda, entretanto, recebe suprimento anual de água maior e melhor distribuído, não sendo, por esse critério, considerada ambientalmente, como parte dessa província fitogeográfica. Pode-se afirmar, portanto, que a mata do Olho d'Água constitui-se numa floresta de transição entre as províncias Atlântica e das Caatingas, tanto florística quanto ambientalmente, com expressiva participação na comunidade de elementos com ampla distribuição pelas florestas secas neotropicais e pelos Cerrados.

\section{Agradecimentos}

Os autores agradecem à direção do Colégio Agrícola de Jundiaí, pelo apoio no trabalho de campo; aos biólogos Marcos Sobral (UFMG), Rita de Cássia Araújo Pereira (IPA), Jorge Tamashiro (UNICAMP) e Maria Iracema Loiola (UFRN), pela identificação de algumas espécies; à CAPES, pelo auxílio financeiro ao primeiro Autor.

\section{Referências bibliográficas}

Andrade-Lima, D. 1953. Notas sobre a dispersão de algumas espécies vegetais no Brasil. Anais da Sociedade de Biologia de Pernambuco 11(1): 25-49.

Andrade-Lima, D. 1954. Contribution to the Study of the Flora of Pernambuco, Brazil. Universidade Rural de Pernambuco, Recife. (série Monografia, n. 1).

Andrade-Lima, D. 1960. Estudos fitogeográficos de Pernambuco. Arquivos do Instituto de Pesquisa Agronômica 5(1): 305-341.

Andrade-Lima, D. 1981. The caatingas dominium. Revista Brasileira de Botânica 4(2): 149-163.

Andrade-Lima, D. 1989. Plantas das Caatingas. Academia Brasileira de Ciências, Rio de Janeiro.

Araújo, F.S.; Sampaio, E.V.S.B.; Rodal, M.J.N. \& Figueiredo, M.A. 1998. Organização comunitária do componente lenhoso de três áreas de carrasco em Novo Oriente, CE. Revista Brasileira de Biologia 58(1): 85-95.

Barbosa, M.R.V.; Mayo, S.J.; Castro, A.A.J.F.; Freitas, G.L.; Pereira, M.S.; Gadelha-Neto, P.C. \& Moreira, H.M. 1996. Cheklist preliminar das angiospermas. Pp. 253-415. In: E.V.S.B. Sampaio; S.J. Mayo \& M.R. de V. Barbosa (eds.). Pesquisa Botânica Nordestina: Progresso e Perspectiva. Sociedade Botânica do Brasil, Recife. 
Burnett, M.R.; August, P.V.; Brown Jr., J.H. \& Killingbeck, K.T. 1998. The influence of geomorphological heterogeneity on biodiversity. I. A patch-scale perspective. Conservation Biology 12(2): 363-370.

Carvalho, D.A.; Oliveira-Filho, A.T.; Vilela, E.A. \& Curi, N. 2000. Florística e estrutura da vegetação arbórea de um fragmento de floresta semidecidual às margens do reservatório da usina hidrelétrica Dona Rita, Itambé do Mato Dentro, MG. Acta Botanica Brasilica 14(1): 37-55.

Cavassan, O.; Cesar, O. \& Martins, F.R. 1984. Fitossociologia da vegetação arbórea da Reserva Estadual de Bauru, Estado de São Paulo. Revista Brasileira de Botânica 7(2): 91-106.

Chiappeta, A.A. 1985. Estudo taxonômico das Loganiaceae para Pernambuco. Dissertação de Mestrado. Universidade Federal Rural de Pernambuco, Recife.

Costa, C.R.A. 1996. Estudo taxonômico de espécies de Chamaecrista Moench (Leguminosae-Caesalpinioideae) ocorrentes no litoral de Pernambuco, Brasil. Dissertação de Mestrado. Universidade Federal Rural de Pernambuco, Recife.

Costa e Silva, M.B. 1996. Estudos taxonômicos do gênero Capparis L. (Capparaceae Juss.) em Pernambuco, Brasil. Dissertação de Mestrado. Universidade Federal Rural de Pernambuco, Recife.

Cottam, G. \& Curtis, J.T. 1956. The use of distance measures in phytosociological sampling. Ecology 37(3): 451-460.

Delaney, M.; Brown, S.; Lugo, A.E.; Torres-Lezama, A. \& Quintero, N.B. 1998. The quality and turnover of dead wood in permanent forest plots in six zones of Venezuela. Biotropica 30(1): 2-11.

Du Bocage, A.L. \& Sales, M.F. 2002. A família Bombacaceae Kunth no Estado de Pernambuco, Brasil. Acta Botanica Brasilica 16(2): 123-139.

Egler, W.A. 1957. O Agreste e os Brejos (Nota de uma excursão a Pernambuco). Boletim Geográfico 138: 294-306.

Eiten, G. 1983. Classificação da Vegetação do Brasil. CNPq, Brasília.

EMBRAPA - Centro Nacional de Pesquisa de Solos. 1997. Manual de métodos de análise de solo. $2^{\mathrm{a}}$ ed. EMBRAPA, CPS, Rio de Janeiro.

EMBRAPA - Centro Nacional de Pesquisa de Solos. 1999. Sistema Brasileiro de Classificação de Solos. EMBRAPA, CPS, Rio de Janeiro.

Fernandes, A. 1998. Fitogeografia Brasileira. Multigraf, Fortaleza

Figueiredo, M.A. 1987. A microrregião salineira norte-riograndense no domínio das caatingas. Coleção Mossoroense 353: 1-44.

Furlan, A. 1996. A Tribo Pisonieae (Nyctaginaceae) no Brasil. Tese de Doutorado. Universidade de São Paulo, São Paulo.
Gentry, A.H. 1988. Changes in plant community diversity and floristic composition on environmental and geographical gradients. Annals of the Missouri Botanical Garden 75(1): 1-34.

Gentry, A.H. 1992. Bignoniaceae - Part II (Tribe Tecomeae). Flora Neotropica, Monografia 25.

Gerhardt, K. \& Hytteborn, H. 1992. Natural dynamics and regeneration methods in tropical dry forests - an introduction. Journal of Vegetation Science 3(3): 361-364.

Gillespie, T.W.; Grijalva, A. \& Farris, C.N. 2000. Diversity, composition, and structure of tropical dry forests in Central America. Plant Ecology 147(1): 37-47.

Holmgren, P.K.; Holmgren, N.H. \& Barnett, L.C. (eds.). 1990. Index herbariorum. Part I: The Herbaria of the World. $8^{\text {th }}$ ed. New York Botanical Garden, Bronx.

Hueck, K. \& Seibert, P. 1981. Vegetationskarte von Südamerika. 2 ed. Gustav Fischer Verlag, Stutgart.

IBGE - Departamento de Recursos Naturais e Estudos Ambientais. 1992. Manual Técnico da Vegetação Brasileira. CDDI-IBGE, Rio de Janeiro. (série Manuais Técnicos de Geociências, n. 1).

IBGE. 1993. Mapa de vegetação do Brasil. $2^{\mathrm{a}} \mathrm{ed}$. IBGE, Rio de Janeiro. Escala 1:5.000.000.

Irwin, H.S. \& Barneby, R.C. 1977. Monographic studies in Cassia (Leg. Caesalpinioideae) IV, Supplementary notes on Section Apoucouita Benth. Brittonia 29(3): 277-290.

Ivanauskas, N.M. \& Rodrigues, R.R. 2000. Florística e fitossociologia de remanescentes de floresta estacional decidual em Piracicaba, São Paulo, Brasil. Revista Brasileira de Botânica 23(3): 291-304.

Jacomine, P.K.T.; Silva, F.B.R.; Formiga, R.A.; Almeida, J.C.; Beltrão, V.A.; Pessôa, S.C.P. \& Ferreira, R.C. 1971. Levantamento exploratório-reconhecimento de solos do Estado do Rio Grande do Norte. SUDENE/Divisão de Pesquisa Pedológica, Recife, v. 1. (série Boletim Técnico, n. 21, série Pedologia, n. 9).

Kent, M. \& Coker, P. 1994. Vegetation description and analysis: A practical approach. John Wiley \& Sons, Chichester.

Landrum, L.R. 1986. Campomanesia, Pimenta, Blepharocalyx, Legrandia, Acca, Myrrhinium and Luma (Myrtaceae). Flora Neotropica, Monografia 45.

Lerdau, M.; Whitbeck, J. \& Holbrook, N.M. 1991. Tropical deciduous forest: death of a biome. Trends in Ecology and Evolution 6(7): 201-202.

Lewis, G.P. 1987. Legumes of Bahia. Royal Botanical Gardens, Kew.

Lewis, G.P. 1998. Caesalpinia: A Revision of the Poincionella - Erythrostemon group. Royal Botanical Gardens, Kew.

Lima, R.B. 1985. Rhamnaceae do Estado de Pernambuco: Aspectos taxonômicos. Dissertação de Mestrado. Universidade Federal Rural de Pernambuco, Recife. 
Lorenzi, H. 1992. Árvores brasileiras: manual de identificação e cultivo de plantas arbóreas nativas do Brasil. v. 1. Editora Plantarum, Nova Odessa.

Lorenzi, H. 1998. Árvores brasileiras: manual de identificação e cultivo de plantas arbóreas nativas do Brasil. v. 2. Editora Plantarum, Nova Odessa.

Mabesoone, J.M.; Campos e Silva, A. \& Beurlen, K. 1972. Estratigrafia e origem do grupo Barreiras em Pernambuco, Paraíba e Rio Grande do Norte. Revista Brasileira de Geociências 2(3): 173-188.

Malavolta, E. 1992. ABC da análise de solos e folha. Editora Agronômica Ceres, São Paulo.

Malavolta, E. \& Kliemann, H.J. 1985. Desordens nutricionais no cerrado. POTAFOS, Piracicaba.

Martins, F.R. 1991. Estrutura de uma Floresta Mesófila. Universidade Estadual de Campinas, Campinas.

Medeiros-Costa, J.T. 1982. As palmeiras (Palmae) nativas em Pernambuco, Brasil. Dissertação de Mestrado. Universidade Federal Rural de Pernambuco, Recife.

Mori, S.A.; Boom, B.M.; Carvalino, A.M. \& Santos, T.S. 1983. Ecological importance of Myrtaceae in an Eastern Brazilian wet forest. Biotropica 15(1): 68-70.

Mueller-Dombois, D. \& Ellenberg, H. 1974. Aims and methods of vegetation ecology. John Wiley \& Sons, New York.

Murphy, P.G. \& Lugo, A.E. 1986a. Ecology of tropical dry forest. Annual Review of Ecology and Systematics 17(1): 67-88.

Murphy, P.G. \& Lugo, A.E. 1986b. Structure and biomass of a subtropical dry forest in Puerto Rico. Biotropica 18(2): 89-96.

Nimer, E. 1972. Climatologia da região Nordeste. Revista Brasileira de Geografia 34(1): 3-51.

Oliveira-Filho, A.T. 1993. Gradient analysis of an area of coastal vegetation in the state of Paraíba, northeastern Brazil. Edinburgh Journal of Botany 50(2): 217-236.

Oliveira-Filho, A.T. \& Carvalho, D.A. 1993. Florística e fisionomia da vegetação no extremo norte do litoral da Paraíba. Revista Brasileira de Botânica 16(1): 115-130.

Oliveira-Filho, A.T. \& Fontes, M.A.L. 2000. Patterns of floristic differentiation among Atlantic forests in southeastern Brazil and the influence of climate. Biotropica 32(4b): 793-810.

Oliveira-Filho, A.T.; Curi, N.; Vilela, E.A. \& Carvalho, D.A. 1998. Effects of canopy gaps, topography, and soils on the distribution of woody species in a central Brazilian deciduous dry forest. Biotropica 30(3): 362-375.

Pereira, O.J. \& Assis, A.M. 2000. Florística da restinga de Camburi, Vitória, ES. Acta Botanica Brasilica 14(1): 99-111.

Phillips, O.L.; Nuñes, U.P. \& Timaná, M.E. 1998. Tree mortality and collecting botanical vouchers in tropical forests. Biotropica 30(2): 298-305.

Pirani, J.R. 1999. Estudos taxonômicos em Rutaceae: Revisão de Helietta e Balfourodendron (Pteleinae); Análise cladística de Pteleinae; Sinopse de Rutaceae do Brasil. Tese de Livre Docência. Universidade de São Paulo, São Paulo.
Pott, A. \& Pott, V.J. 1994. Plantas do Pantanal. EMBRAPA, CPAP, Brasília.

Prado, D.E. 2000. Seasonally dry forests of tropical South America: from forgotten ecosystems to a new phytogeographic unit. Edinburgh Journal of Botany 57(3): 437-461.

Prado, D.E. \& Gibbs, P.E. 1993. Pattern of species distributions in the dry seasonal forests of South America. Annals of the Missouri Botanical Garden 80(4): 902-927.

Ranzani, G.; Freire, O.; Kinjo, T. \& Cesar, C.M. 1964. Considerações gerais sobre os solos de tabuleiro do Nordeste. Boletim de Recursos Naturais, Recife, 2(1): 45-70.

Ratter, J.A. 1992. Transitions between Cerrado and forest vegetation in Brazil. Pp. 417-429. In: P.A. Furley; J. Proctor \& J.A. Ratter (eds.). Nature and dynamics of forest-savanna boundaries. Chapman \& Hall, London.

Ratter, J.A.; Bridgewater, S.; Ribeiro, J.F.; Dias, T.A.B. \& Silva, M.R. 2000. Estudo preliminar da distribuição das espécies lenhosas da fitofisionomia cerrado sentido restrito nos estados compreendidos pelo bioma cerrado. Boletim do Herbário Ezechias Paulo Heringer 5(1): 5-43.

Reis, A.C.S. 1976. Clima da Caatinga. Anais da Academia Brasileira de Ciências 48(2): 325-335.

Rizzini, C.T. 1979. Tratado de fitogeografia do Brasil: Aspectos sociológicos e florísticos. v. 2. Hucitec Ed., São Paulo.

Rodal, M.J.N.; Andrade, K.V.A.; Sales, M.F. \& Gomes, A.P.S. 1998. Fitossociologia do componente lenhoso de um refúgio vegetacional no município de Buíque, Pernambuco. Revista Brasileira de Biologia 58(3): 517-526.

Rodrigues, R.R. \& Nave, A.G. 2000. Heterogeneidade florística das matas ciliares. Pp. 45-71. In: R.R. Rodrigues \& H.F. Leitão-Filho (eds.). Matas Ciliares: conservação e recuperação. Editora da Universidade de São Paulo \& Fapesp, São Paulo.

Sabogal, C. 1992. Regeneration of tropical dry forests in Central America, with examples from Nicaragua. Journal of Vegetation Science 3(3): 407-416.

Salgado, O.A.; Jordy-Filho, S. \& Cardoso-Gonçalves, L.M. 1981. Vegetação: As regiões fitoecológicas, sua natureza e seus recursos econômicos; estudo fitogeográfico. Pp. 485-544. In: Brasil - Projeto RADAMBRASIL. Folhas SB. 24/25 Jaguaribe/Natal. Projeto RADAMBRASIL, Rio de Janeiro. (série Levantamento de Recursos Naturais, v. 23).

Sarmiento, G. 1975. The dry plant formations of South America and their floristic connections. Journal of Biogeography 2(2): 233-251.

Silva, G.C. \& Nascimento, M.T. 2001. Fitossociologia de um remanescente de mata sobre tabuleiros no norte do Estado do Rio de Janeiro (Mata do Carvão). Revista Brasileira de Botânica 24(1): 51-62.

Silva, M.A. 1980. O gênero Calliandra Benth. Leguminosae no Brasil. Dissertação de Mestrado, Universidade Federal Rural de Pernambuco, Recife.

Sleumer, H.O. 1980. Flacourtiaceae. Flora Neotropica, Monografia 22.

Sleumer, H.O. 1984. Olacaceae. Flora Neotropica, Monografia 38. 
Soares-Filho, A.O. 2000. Estudo fitossociológico de duas florestas em região ecotonal no planalto de Vitória da Conquista, Bahia, Brasil. Dissertação de Mestrado. Universidade de São Paulo, São Paulo.

Souza, C.G.; Viana, C.D.B.; Wake, M. \& Costa, V.S. 1981. Pedologia: Levantamento exploratório de solos. Pp. 349-484. In: Brasil - Projeto RADAMBRASIL. Folhas SB. 24/25 Jaguaribe/Natal. Projeto RADAMBRASIL, Rio de Janeiro. (série Levantamento de Recursos Naturais, v. 23).

Trindade, A. 1991. Estudo florístico e fitossociológico do estrato arbustivo-arbóreo de um trecho de floresta arenícola costeira do Parque Estadual das Dunas, Natal (RN). Dissertação de Mestrado. Universidade Federal Rural de Pernambuco, Recife.
Wutke, A.C.P. 1972. Acidez. Pp. 149-168. In: A.C. Moniz (coord.). Elementos de Pedologia. Editora da Universidade de São Paulo \& Ed. Polígono, São Paulo. Wutke, A.C.P. \& Camargo, O.A. 1972. Adsorção e troca iônica. Pp. 125-147. In: A.C. Moniz (coord.). Elementos de Pedologia. Editora da Universidade de São Paulo \& Ed. Polígono, São Paulo.

Zar, J. 1999. Biostatistical Analysis. $4^{\text {th }}$ ed. Prentice Hall, New Jersey.

Zappi, D.C. 1994. Pilosocereus (Cactaceae): The Genus in Brazil. Royal Botanical Gardens, Kew. 